\title{
Laboratory studies of the chemical composition and cloud condensation nuclei (CCN) activity of secondary organic aerosol (SOA) and oxidized primary organic aerosol (OPOA)
}

\author{
A. T. Lambe ${ }^{1,2}$, T. B. Onasch ${ }^{1,2}$, P. Massoli ${ }^{2}$, D. R. Croasdale ${ }^{1}$, J. P. Wright ${ }^{1}$, A. T. Ahern ${ }^{1,2}$, L. R. Williams ${ }^{2}$, D. R. \\ Worsnop $^{2}$, W. H. Brune ${ }^{3}$, and P. Davidovits ${ }^{1}$ \\ ${ }^{1}$ Chemistry Department, Boston College, Chestnut Hill, MA, USA \\ ${ }^{2}$ Aerodyne Research Inc., Billerica, MA, USA \\ ${ }^{3}$ Department of Meteorology and Atmospheric Sciences, The Pennsylvania State University, State College, PA, USA
}

\section{Supporting Information}

\section{1 laboratory SOA and OPOA precursors}

Figure $\mathrm{S} 1$ shows molecular structures for twelve of the fourteen precursors studied in the present work; diesel fuel and 10W-30 engine lubricating oil are not shown. As discussed in Section 2.3, SOA particles were generated via gasphase oxidation of volatile organic compounds (VOCs) and intermediate-volatility organic compounds (IVOCs) in the PAM. The VOC precursors used in this study were $n$-decane $\left(n\right.$ - $\left.\mathrm{C}_{10}\right)$, isoprene, $\alpha$-pinene, $\beta$-pinene, toluene, $\mathrm{m}$-xylene, and mesitylene. The IVOC precursors used in this study were $n$-heptadecane $\left(n-\mathrm{C}_{17}\right)$, diesel fuel, longifolene, and naphthalene. OPOA was generated by heterogenous oxidation of bis(2-ethylhexyl) sebacate (BES) and 10W-30 engine lubricating oil particles. Another set of experiments was conducted with an internally mixed primary aerosol composed of glyoxal and ammonium sulfate.

\section{2 thermally denuded PAM-generated SOA}

In a subset of experiments, an Aerodyne thermal denuder (Huffman et al., 2008) was placed upstream of the AMS and SMPS to investigate the chemical composition of PAMgenerated SOA as a function of organic aerosol concentration. The heated section of the thermal denuder was set to several constant temperatures $\left(\mathrm{T}=60-250^{\circ} \mathrm{C}\right)$ and allowed to equilibrate before measurements. Combined flows through the thermal denuder ranged between $2-3 \mathrm{lpm}$, corresponding to residence times of 3-5 sec and 3-4 sec in the heater and denuder sections, respectively. Figure $\mathrm{S} 2$ shows $f_{44}$ versus $f_{43}$ for thermally denuded SOA generated from naphthalene and $\alpha$-pinene oxidation in the PAM. As is evident, thermally denuding the aerosol increases $f_{44}$ and decreases $f_{43}$.
At a specific $\mathrm{OH}$ exposure, $f_{44}$ of $\alpha$-pinene SOA increased by $12 \%-26 \%$ as a function of thermal denuding, accompanied by a $15 \%$ - $33 \%$ decrease in $f_{43}$. Likewise, the $f_{44}$ of naphthalene SOA increased by $6 \%-232 \%$, accompanied by a $12 \%-17 \%$ decrease in $f_{43}$. Similar trends were observed by lowering the SOA precursor concentration that was input to the PAM. These results are consistent with OOA at $m / z=43$ and $m / z=44$ representing semivolatile and low-volatilty organics, respectively.

\subsection{PAM-generated SOA containing $f_{43}$ curvature}

Figure S3 shows $f_{44}$ as a function of $f_{43}$ for SOA generated from nine of the fourteen precursors in the PAM. These SOA systems were characterized by increases and subsequent decreases in $f_{43}$ with oxidation, suggesting the formation and decay of early-generation oxidation products containing high $f_{43}$ (specifically, $\mathrm{C}_{2} \mathrm{H}_{3} \mathrm{O}^{+}$ions).

\section{$1.4 \mathrm{O} / \mathrm{C}-\boldsymbol{f}_{44}$ and H/C- $\boldsymbol{f}_{43}$ of PAM-generated SOA}

Figures $\mathrm{S} 4 \mathrm{a}$ and $\mathrm{S} 4 \mathrm{~b}$ shows $\mathrm{O} / \mathrm{C}$ ratio as a function of $f_{44}$ and $\mathrm{H} / \mathrm{C}$ ratio as a function of $f_{43}$ for PAM-generated SOA and OPOA. The dashed line Fig. S4a $\left(\mathrm{O} / \mathrm{C}=3.82 \times f_{44}+0.0794\right)$ is the best fit to multiple laboratory and field datasets (Aiken et al., 2008). The black dashed line in Fig. S4b $(\mathrm{H} / \mathrm{C}=1+$ $\left.5.16 \times f_{43} \quad 8.85 \times f_{43}{ }^{2}\right)$ is a quadratic fit to smog chamber and field data (Ng et al., 2011b); grey dashed lines represent $10 \%$ confidence intervals to the quadratic fit as presented by $\mathrm{Ng}$ et al. 


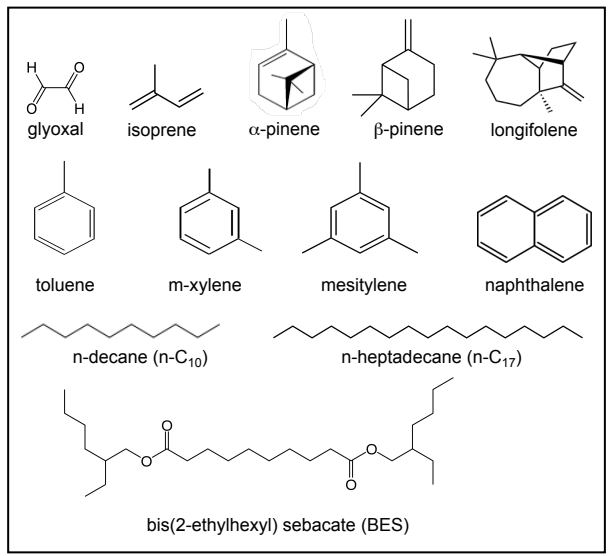

Fig. S1. Molecular structures of gas- and condensed-phase oxidized organic aerosol precursors used in this study.

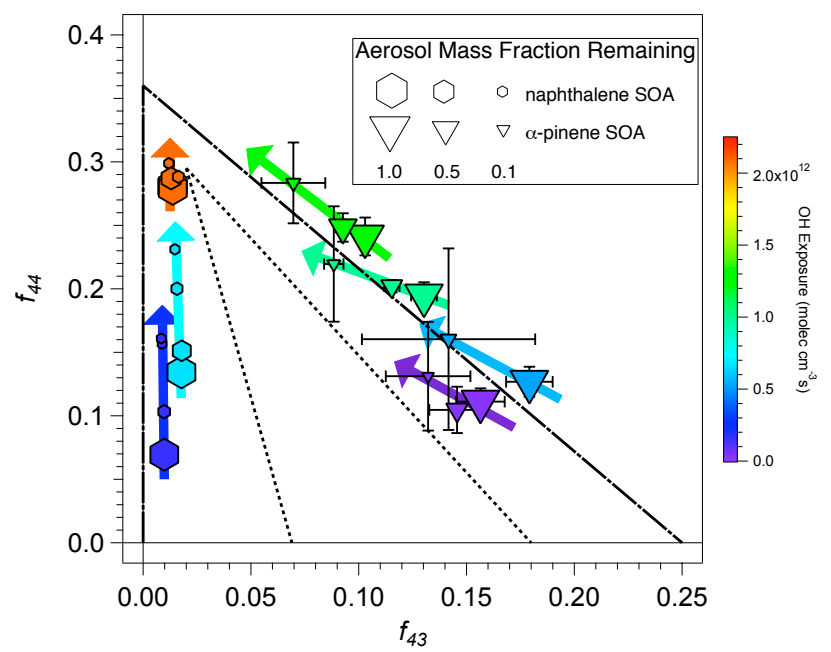

Fig. S2. $f_{44}$ shown as a function of $f_{43}$ for thermally denuded naphthalene and $\alpha$-pinene SOA. Symbols are colored by OH exposure in the PAM and sized by aerosol mass fraction remaining (relative to non-denuded conditions). Error bars represent $\pm 1 \sigma$ in measurements. Dashed lines indicate range of ambient $f_{44}$ and $f_{43}$ measurements, while dashed-and-dotted lines indicate range of laboratory PAM measurements. 


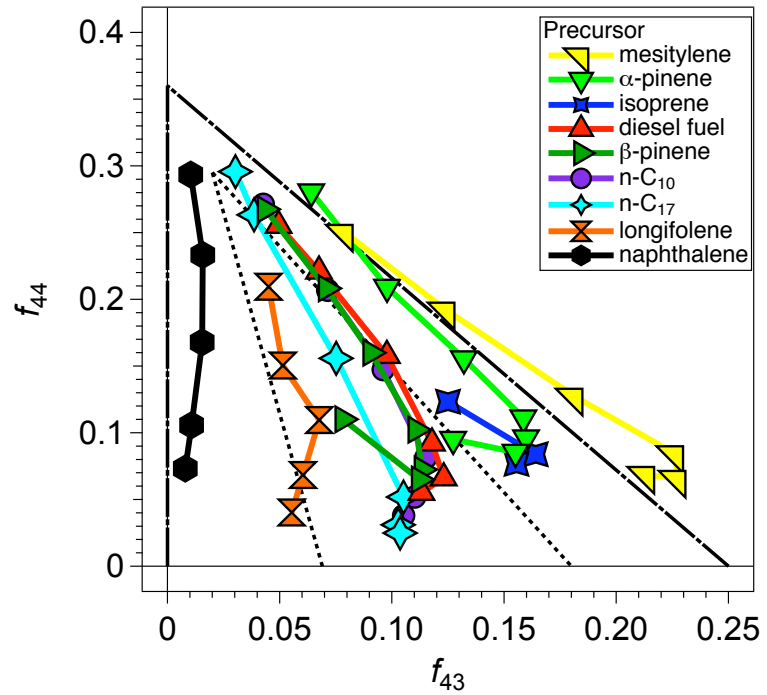

Fig. S3. $f_{44}$ shown as a function of $f_{43}$ for PAM-generated SOA characterized by $f_{44}-f_{43}$-curvature (replotted from Fig. 2). Dashed lines indicate range of ambient $f_{44}$ and $f_{43}$ measurements, while dashed-and-dotted lines indicate range of laboratory PAM measurements. 

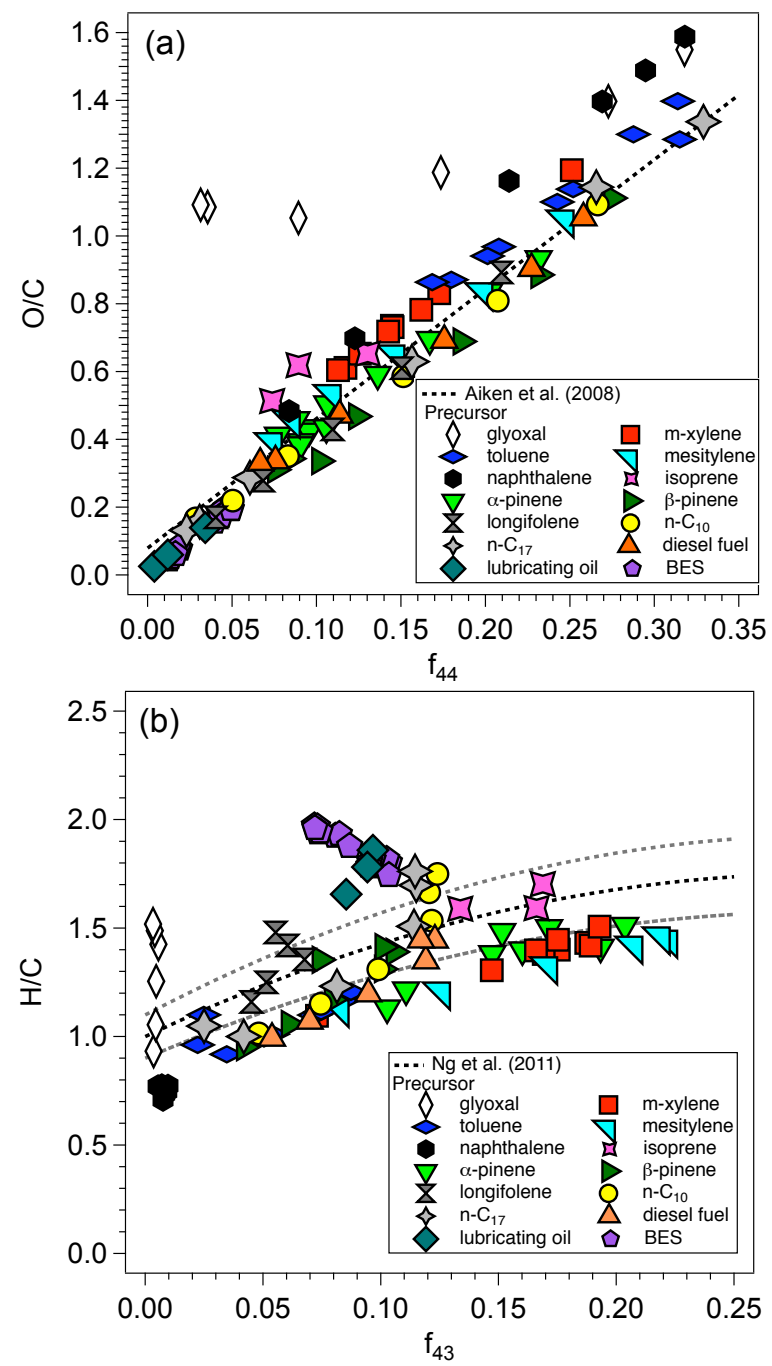

Fig. S4. (a) Oxygen-to-carbon $(\mathrm{O} / \mathrm{C})$ ratio as a function of $f_{44}$ and (b) hydrogen-to-carbon (H/C) ratio as a function of $f_{43}$ for PAM-generated SOA and OPOA. Dashed lines represent O/C $f_{44}$ and H/C- $f_{43}$ parameterizations from Aiken et al. (2008) and Ng et al. (2011b) respectively. Glyoxal OPOA (diamonds) deviates from Aiken et al. and $\mathrm{Ng}$ et al. parameterizations for reasons described in the text. 